\title{
Breast carcinoma metastasis to the lacrimal gland: Two case reports
}

\author{
MARIE N. NICKELSEN ${ }^{1}$, SARAH VON HOLSTEIN ${ }^{1,2}$, ALASTAIR B. HANSEN ${ }^{3}$, \\ JAN U. PRAUSE ${ }^{1}$ and STEFFEN HEEGAARD ${ }^{1,2}$ \\ ${ }^{1}$ Eye Pathology Section, University of Copenhagen, Copenhagen $2100 ;{ }^{2}$ Department of Ophthalmology, \\ University Hospital Glostrup, Glostrup, Greater Copenhagen 2600; ${ }^{3}$ Department of Pathology, \\ Copenhagen University Hospital at Herlev, Copenhagen 2730, Denmark
}

Received August 17, 2014; Accepted May 12, 2015

DOI: $10.3892 / 01.2015 .3282$

\begin{abstract}
A 77-year-old female, with proptosis, reduced eye motility and diplopia which had developed over two to three months and a 69-year-old female with proptosis, oedema of the eyelid, reduced motility and ptosis, which had developed over three weeks, are presented in the present study. Computed tomography scans revealed irregular lacrimal gland tumours in the two patients. The two patients had history of breast cancer. The first breast cancer metastasis in the lacrimal gland demonstrated a cribriform growth pattern containing ductal elements. The epithelial tumour cells stained positive for cytokeratin (1-8, 10, 14-16, 18 and 19), oestrogen receptor, epithelial membrane antigen (EMA), carcinoembryonic antigen (CEA) and gross cystic disease fluid protein 15 (GCDFP-15). The second metastatic tumour was positive for EMA and estrogen receptor, but variably positive for CEA and GCDFP-15. The metastasis in the lacrimal gland was a pleomorphic tumour. The tumour cells were positive for EMA and variably positive for oestrogen and CEA. Metastases to the lacrimal gland are extremely rare, and metastases to the lacrimal gland should be considered in the diagnoses of lacrimal gland tumours. The present study aimed to describe two such cases and draw attention to breast carcinomas as a differential diagnosis and the most frequent cause of lacrimal gland metastasis.
\end{abstract}

\section{Introduction}

Lacrimal gland tumours are uncommon. The most common type of malignant lacrimal gland tumour are epithelial tumours, including adenoid cystic carcinoma, which are responsible for $58 \%$ of all malignant tumours in the lacrimal gland (1).

Correspondence to: Mr. Steffen Heegaard, Eye Pathology Section, University of Copenhagen, 11 Frederik V's Vej, Copenhagen 2100, Denmark

E-mail: sthe@sund.ku.dk

Key words: lacrimal gland, metastasis, breast cancer, pathology, immunohistochemistry
Metastases to the lacrimal gland are rare (2) and only sporadic cases have previously been reported. The gland may also be a site of direct invasion from a neighbouring tumour (3).

Breast cancer is considered one of the most frequent solid tumours to metastasize to the eye region $(4,5)$. However, only one previous report has described breast cancer metastasizing to the lacrimal gland (2). Breast cancer metastasis to the salivary gland, to which the lacrimal gland is often compared, is considered markedly more common (6).

The present study reports two cases of metastases to the lacrimal gland from breast cancer, presenting with massive proptosis and a poor prognosis. Written informed consent for the publication of this report was obtained from each patient or their family.

\section{Case reports}

Case 1. A 77-year-old female was referred to the ophthalmological department with a suspected retrobulbar tumour, due to a rapidly (2-3 months) progressing left-sided proptosis (Fig. 1A).

Examination revealed a proptosis of $11 \mathrm{~mm}$, accompanied by increased retrobulbar resistance. Eye motility was reduced and when looking up and to the left the patient complained of diplopia. The skin over the temporal orbital border was thickened but without palpable tumour. Visual acuity was $6 / 60$ in the right eye and 1/60 in the left eye. The intraocular pressure was $20 \mathrm{mmHg}$ in the right eye and $29 \mathrm{mmHg}$ in the left eye. A computed tomography (CT) scan revealed a $4-\mathrm{cm}$ tumour located laterally and superiorly to the left eyeball. The tumour infiltrated the lateral and superior rectus muscle, and eroded the lateral orbital wall and roof (Fig. 1B). The tumour had spread intracranially to the frontal region of the brain and had a $1 \mathrm{~cm}$ bone metastasis in the frontal region of the cranium. A bone scintigraphy revealed multiple pathological areas of increased activity, which explained the skeletal pain the patient had experienced.

An incisional biopsy of the lacrimal gland tumour was performed.

Eleven years previously a mammography had identified a dense area with microcalcifications in the upper lateral quadrant of the patient's left breast. There was no palpable process. 


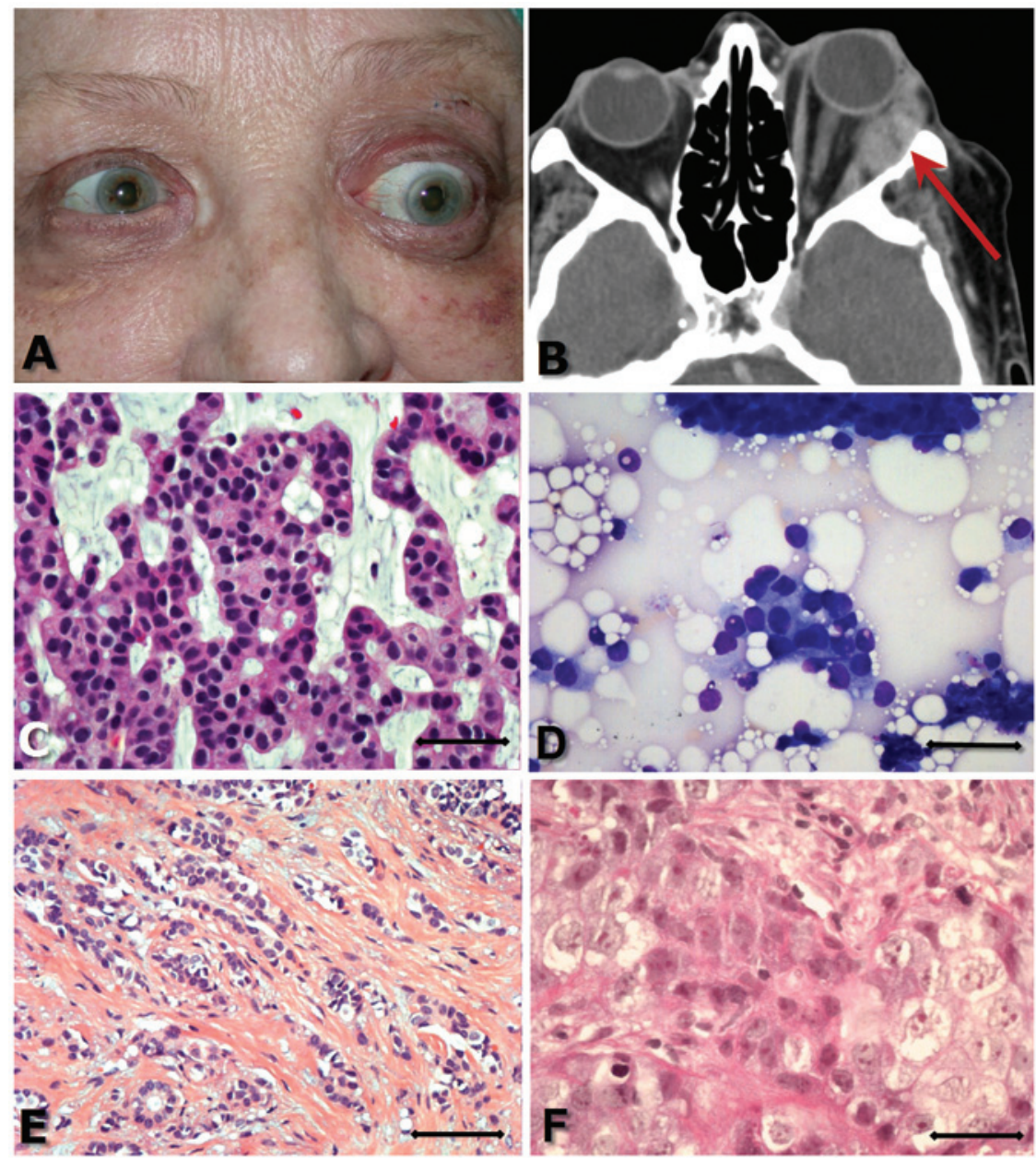

Figure 1. Characteristics of patients 1 and 2. (A) Left-sided proptosis and displacement of the eye of patient 1. (B) Computed tomography scan of the orbit demonstrating a 4-cm tumour (red arrow) located laterally and superiorly to the left eyeball (patient 1). (C) Epithelial tumour with a cribriform growth pattern in the lacrimal gland (HE; scale bar, $80 \mu \mathrm{m}$ ) (patient 1). (D) Fine-needle aspiration from the tumour in the left breast revealed slightly pleomorfic, epithelial cells arranged in groups or as single cells in a mucoid material (HE; scale bar, $40 \mu \mathrm{m}$ ) (patient 1). (E) Breast tumour of patient 2 demonstrated tumour cells arranged in solid clusters or trabeculi (HE; scale bar, $200 \mu \mathrm{m}$ ). (F) Lacrimal tumour of patient 2 demonstrated glandular tumour islands containing pleomorfic epithelial tumour cells with prominent nucleoli (HE; scale bar, $50 \mu \mathrm{m})$.HE, haemotoxylin and eosin stain.

The patient refused treatment. A further mammography conducted three months later demonstrated growth of the tumour and fine needle aspiration revealed malignant tumour cells. Growth of the tumour was monitored during the next five years by control mammographies and ultrasound. During these years a fine needle aspiration revealed an invasive ductal carcinoma. The patient still refused treatment and no further mammographies or clinical control measures were performed.

Following diagnosis of the orbital metastasis the patient received palliative radiotherapy ten times towards the left eye resulting in a cumulative subdosis of $29 \mathrm{~Gy}$. The patient died nine months following first contact with the ophthalmological department.

Case 2. A 69-year-old female was referred due to proptosis of the right eye, which had developed over three weeks. Clinical examination revealed proptosis of $5 \mathrm{~mm}$, oedema of the right upper eyelid and ptosis. Movement capabilities of the right eye were significantly reduced when the patient looked up, and slightly reduced abduction and adduction were observed. A tumour could be palpated supero-temporally in the right orbit at the site of the lacrimal gland and extending laterally. The tumour was adherent to the neighbouring structures. Visual acuity was 0.8 in the right eye and 1.0 in the left eye. A magnetic resonance imaging scan revealed a $1 \times 2 \times 3 \mathrm{~cm}$ tumour proximal to the lacrimal gland. A biopsy of the lacrimal gland tumour was performed.

A bone scintigraphy demonstrated multiple areas of increased activity and an abdominal ultrasound identified a focal process in the liver. A liver biopsy revealed breast cancer metastasis.

One year previously, the patient had been diagnosed with a tumour in the left breast. The tumour was $0.5 \mathrm{~cm}$ in diameter and localised proximal to the areola. An ultrasound guided biopsy (including fine needle aspiration as well as core biopsy) was conducted and microscopy revealed an invasive ductal carcinoma. A mastectomy was performed and ten axillary lymph nodes were removed. Histological examination demonstrated the carcinoma to be oestrogen receptor positive.

Following diagnosis of the orbital tumour the patient received radiotherapy (3 Gy x10), and a cycle of cyclofosfamid $1200 \mathrm{mg}$, Methotrexat $95 \mathrm{mg}$ and 5-fluoracil $1200 \mathrm{mg}$ was administered. The radiation therapy reduced the swelling around the eye, proptosis was reduced to $2 \mathrm{~mm}$ and normal movement of the 
Table I. Immunohistochemical analysis of lacrimal gland tumours and ductal breast carcinomas of patients 1 and 2 .

\begin{tabular}{|c|c|c|c|c|c|}
\hline \multirow[b]{2}{*}{$\begin{array}{l}\text { Immunohistochemical } \\
\text { marker }\end{array}$} & \multicolumn{2}{|c|}{ Patient 1} & \multicolumn{2}{|c|}{ Patient 2} & \multirow[b]{2}{*}{$\begin{array}{c}\text { Breast carcinoma staining } \\
\text { pattern in literature, }(\mathrm{ref})\end{array}$} \\
\hline & $\begin{array}{l}\text { Lacrimal gland } \\
\text { tumour }\end{array}$ & $\begin{array}{l}\text { Ductal breast } \\
\text { carcinoma }\end{array}$ & $\begin{array}{l}\text { Lacrimal gland } \\
\text { tumour }\end{array}$ & $\begin{array}{l}\text { Ductal breast } \\
\text { carcinoma }\end{array}$ & \\
\hline Pan-CK 1-8,10,14-16,18,19 & + & & + & + & Positive $(7,8)$ \\
\hline CEA & + & & $(+)$ & $(+)$ & $45-58 \%(9)$ \\
\hline EMA & + & & + & + & $93 \%(10)$ \\
\hline ER & + & - & $(+)$ & + & $70-80 \%(7,11,12)$ \\
\hline GCDFP-15 & + & & - & $(+)$ & $50-74 \%(7,12)$ \\
\hline GFA & $(+)$ & & - & - & $7 \%(13)$ \\
\hline HER-2 & - & & - & - & $15-20 \%(14)$ \\
\hline Mammaglobin A & - & & - & - & $23-47 \%(15)$ \\
\hline PR & - & & - & - & $54-70 \%(7,11,12)$ \\
\hline S100 & - & & - & - & $10-45 \%(7,8,12,14)$ \\
\hline SMA & - & & - & - & Negative (7) \\
\hline Vimentin & - & & - & - & $64 \%(16)$ \\
\hline
\end{tabular}

Table II. Previously reported metastases to the lacrimal gland.

\begin{tabular}{|c|c|c|c|c|c|}
\hline Tumour type & Gender & Age, years & Treatment & Reference & Publication \\
\hline Breast carcinoma & - & - & - & (2) & $1998 \mathrm{~A}$ \\
\hline Breast carcinoma & - & - & - & $(2)$ & 1998 B \\
\hline Breast carcinoma $^{a}$ & Female & 77 & Radiotherapy & Present case 1 & \\
\hline Breast carcinoma $^{a}$ & Female & 69 & Radiotherapy, Tamoxifen & Present case 2 & \\
\hline Carcinoid & - & - & - & (17) & 1982 \\
\hline Carcinoid, ileum & Male & 51 & Resection & (18) & 1956 \\
\hline Carcinoid, mediastinum & Male & 82 & Surgery & (19) & 1989 \\
\hline Renal cell carcinoma & Male & 59 & Surgery & (20) & 1999 \\
\hline Renal cell carcinoma & Male & 65 & Surgery & $(21)$ & 1986 \\
\hline Thyroid carcinoma & Female & 56 & & $(22)$ & 1990 \\
\hline Unknown & - & - & - & $(2)$ & 1998 \\
\hline
\end{tabular}

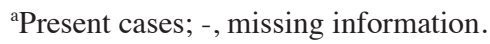

eye was regained. However, the patient was not well enough to receive the second series of chemotherapy. Shortly prior to death, the patient commenced treatment with Tamoxifen based on an estrogen receptor-positive breast cancer. The patient died three months following referral to the eye department.

Histopathology. The applied antibodies are listed in Table I. The breast tumour smear from patient one was only stained with haematoxylin and eosin and an antibody against oestrogen receptors due to the small specimen sample available.

\section{Microscopy}

Case 1. Biopsy from the lacrimal gland revealed an epithelial tumour tissue with a cribriform growth pattern containing ductal elements (Fig. 1C). There were scattered lumina in the epithelial clusters. The epithelial cells appeared well differentiated and there was no invasion into the surrounding stromal tissue. Few mitoses were observed. The background was mucinous and stained positive with Alcian blue. Immunohistochemistry indicated a positive reaction for pan-cytokeratin (CK), estrogen receptor, epithelial membrane antigen (EMA), carcinoembryonic antigen (CEA) and gross cystic disease fluid protein 15 (GCDFP-15). There was variable staining for glial fibrillary acidic protein but the tumour cells were negative for progesterone, human epidermal growth factor receptor 2 (HER-2) and mammaglobin.

Fine needle aspiration from the tumour in the left breast revealed epithelial cells with slight pleomorphism, arranged 
in groups or as single cells. There were no myoepithelial cells, but in certain areas mucoid material was identified (Fig. 1D).

The cytology of the breast tumour and the histology of the lesion in the lacrimal gland were consistent with a diagnosis of an invasive ductal, partly mucinous, breast carcinoma with metastasis to the lacrimal gland.

Case 2. The lacrimal gland tumour consisted of closely arranged areas of glandular epithelial tumour islands of varying size, surrounded by sparse collagenous stroma containing a proportion of inflammatory cells. The tumour cells were pleomorphic with a lightly eosinophilic cytoplasm and nuclei with prominent nucleoli (Fig. 1F). There were small necroses, and mitotic figures were identifiable. Immunohistochemistry revealed a positive reaction for pan-CK, EMA and oestrogen receptor, variable positivity for CEA and a negative reaction for GCDFP-15, progesterone, HER-2 and mammaglobin.

The breast tumour was an invasive ductal carcinoma, comprised of cells with moderate pleomorphism, arranged in small, solid clusters or trabeculi (Fig. 1E). The eosinophilic or clear cytoplasm was moderate to abundant. Focally, an in situ component was demonstrated. Immunohistochemically, the tumour was found to be positive for EMA and estrogen receptor, with variable positivity for pan-CK, CEA and GCDFP-15 and negative reaction for progesterone, HER-2 and mammaglobin.

Due to the similar morphology and immunohistochemical profile, the tumour in the lacrimal gland was regarded as a metastasis from the ductal carcinoma of the breast.

\section{Discussion}

The two patients in the present study presented with ptosis, increased retrobulbar resistance, diplopia, reduced eye movement and proptosis. All of these findings are typical of primary, as well as secondary, lacrimal gland tumours (23). Malignant lacrimal gland tumours typically induce symptoms six months following development (24), although this was even more rapid in the present cases of metastasis.

In addition to histology, histochemistry and immunohistochemistry are able to aid clarification of the diagnosis of breast cancer metastasis. However, there is no single specific marker that may reliably diagnose a breast cancer metastasis. The importance of establishing the correct diagnosis is important due to the varying treatment modalities of breast cancer metastases (25).

GCDFP-15 and mammaglobin have been considered to be specific markers of breast carcinomas. GCDFP-15 is regarded to have high specificity, whereas mammaglobin has a high sensitivity (26). A combination of GCDFP-15 and mammaglobin staining is recommended for the diagnosis of metastatic breast cancer $(14,27)$. When possible, it is also preferable to compare the primary breast tumour to the suspected metastasis. In the two present cases, GCDFP-15 was variably positive and the metastases were mammaglobin negative.

The CK panel used in the present study consisted of CK 1-8, 10, 14-16, 18 and 19. In normal breast tissue the luminal cells express CK 7, 8, 18 and 19 and the basal cells express CK 5/6, 14 and 17 (7,14). In lacrimal glands the secretory and basal ductal cells have also been found to be CK 7, 8, 18 and 19 positive (28). Therefore, it is not possible to differentiate between a primary epithelial lacrimal gland tumour and a metastasis from a ductal breast carcinoma using CKs.

The lacrimal gland is often compared to the salivary gland due to their shared embryonic origins. In the salivary gland $1-8 \%$ of all malignancies are found to be metastatic tumours $(29,30)$. Tumours in the salivary glands are markedly more common than those in the lacrimal gland, and there are more metastases to the salivary glands than to the lacrimal glands (31). A plausible explanation for this phenomenon is the presence of lymph nodes in the salivary glands, in contrast to the lacrimal gland. The spread of breast cancer to the salivary glands may therefore occur by haematogenous or lymphatic spread. Metastases to the sublingual gland, which is also without lymph nodes, has never been reported (31).

Consideration should also be given to metastasis-associated genes, where a specific genetic profile may increase the risk of organ-specific metastasis (32).

The general treatment of breast cancer and breast cancer metastases is individualised and may consist of surgery, radiation and systemic therapy $(33,34)$. Depending on the initial stage, tumour biology and primary treatment strategy, $20-85 \%$ of patients diagnosed with early breast cancer will later develop recurrent and/or metastatic breast cancer (33). The two patients in the present study received radiotherapy and patient two also received chemotherapy and, shortly prior to mortality, began treatment with Tamoxifen.

Metastases to the lacrimal gland are rare (Table II). The present cases demonstrate that the clinician should consider breast cancer metastasis in the differential diagnosis of lacrimal gland tumours, particularly if symptoms develop rapidly. Such lacrimal gland metastases may be histologically difficult to differentiate from other epithelial lacrimal gland tumours. The results of the present study draw attention to breast cancer being one of the most frequent causes of metastasis to the lacrimal gland.

\section{Acknowledgements}

The authors would like to thank Søren Daugaard (Department of Pathology, Rigshospitalet, University of Copenhagen, Denmark) for his valuable comments. The present study was supported by The Danish Eye Research Foundation, The Danish Eye Health Society, Synoptik-Fonden, Købmand Kristjan Kjær and wife Magrethe Kjær's Foundation, Kleinsmed Svend Helge Arvid Schrøder and wife Ketty Lydia Larsen Schrøder's Foundation, DMSc Alfred Helsted and wife DMSc Eli Møller's Foundation and Engineer August Fredrik Wedell Erichsen's Foundation.

\section{References}

1. von Holstein SL, Therkildsen MH, Prause JU, Stenman G, Siersma VD and Heegaard S: Lacrimal gland lesions in Denmark between 1974 and 2007. Acta Ophthalmol 91: 349-354, 2013.

2. Font RL, Smith SL and Bryan RG: Malignant epithelial tumors of the lacrimal gland: A clinicopathologic study of 21 cases. Arch Ophthalmol 116: 613-616, 1998.

3. Font RL, Croxatto JO and Rao NA (eds): Tumors of the lacrimal gland. In: Tumors of the Eye and Ocular Adnexa. $4^{\text {th }}$ edition. American Registry of Pathology/Armed Forces Institute of Pathology, Washington, pp223-246, 2006. 
4. Mejía-Novelo A, Alvarado-Miranda A, Morales-Vázquez F, Gamboa-Vignole C, Núñez-Gómez R, Castañeda-Soto N, DueñasGonzález A, Candelaria-Hernández M and Lara-Medina F: Ocular metastases from breast carcinoma. Med Oncol 21: 217-221, 2004.

5. Mennel RG: Ocular metastases from breast cancer. Clin Breast Cancer 1: 318-319, 2001.

6. Löning T and Jäkel KT: Tumours of the salivary glands - secondary tumours. In: World Health Organization Classification of Tumours: Pathology and Genetics, Head and Neck Tumours Barnes L, Eveson JW, Reichart P and Sidransky D (eds). IARC Press, Lyon, p281, 2005.

7. Yeh IT and Mies C: Application of immunohistochemistry to breast lesions. Arch Pathol Lab Med 132: 349-358, 2008.

8. Hicks DG: Immunohistochemistry in the diagnostic evaluation of breast lesions. Appl Immunohistochem Mol Morphol 19: 501-505, 2011

9. Mauri FA, Caffo O, Veronese S, Verderio P, Boracchi P, Bonzanini M, Rossi N, Perrone G, Dalla Palma P and Barbareschi M: Tissue carcinoembryonic antigen and oestrogen receptor status in breast carcinoma: An immunohistochemical study of clinical outcome in a series of 252 patients with long-term follow-up. Br J Cancer 77: 1661-1668, 1998.

10. van der Vegt B, de Roos MA, Peterse JL, Patriarca C, Hilkens J, de Bock GH and Wesseling J: The expression pattern of MUC1 (EMA) is related to tumour characteristics and clinical outcome of invasive ductal breast carcinoma. Histopathology 51: 322-335, 2007.

11. Ellis IO, Schnitt SJ, Sastre-Garau X, Bussolati G, Tavassoli FA, Eusebi V, et al: Tumours of the breast. In: Tumours of the Breast and Female Genital Organs. Tavassol FA and Devilee P (eds) IARC Press, Lyon, pp9-112, 2003.

12. Lee AH: Use of immunohistochemistry in the diagnosis of problematic breast lesions. J Clin Pathol 66: 471-477, 2013

13. Gould VE, Koukoulis GK, Jansson DS, Nagle RB, Franke WW and Moll R: Coexpression patterns of vimentin and glial filament protein with cytokeratins in the normal, hyperplastic, and neoplastic breast. Am J Pathol 137: 1143-1155, 1990.

14. Bhargava R, Esposito N and Dabbs DJ: Immunohistology of the breast. In: Diagnostic Immunohistochemistry Theranostic and Genomic Applications. $3^{\text {rd }}$ edition. Dabbs DJ (ed). Elsevier Saunders, Philadelphia, pp763-819, 2010.

15. Watson MA and Fleming TP: Mammaglobin, a mammary-specific member of the uteroglobin gene family, is overexpressed in human breast cancer. Cancer Res 56: 860-865, 1996

16. Raymond WA and Leong AS: Co-expression of cytokeratin and vimentin intermediate filament proteins in benign and neoplastic breast epithelium. J Pathol 157: 299-306, 1989.

17. Divine RD, Anderson RL and Ossoinig KC: Metastatic carcinoid unresponsive to radiation therapy presenting as a lacrimal fossa mass. Ophthalmology 89: 516-520, 1982.

18. Font RL and Ferry AP: Carcinoma metastatic to the eye and orbit III. A clinicopathologic study of 28 cases metastatic to the orbit. Cancer 38: 1326-1335, 1976.

19. Harris DC, Clark CV and Bartholomew RS: Carcinoid tumour in the lacrimal gland. Doc Ophthalmol 73: 43-51, 1989.
20. Shields JA, Shields CL, Eagle RC Jr, Singh AD and Armstrong T: Metastatic renal cell carcinoma to the palpebral lobe of the lacrimal gland. Ophthal Plast Reconstr Surg 17: 191-194, 2001.

21. Denby P, Harvey L and English MG: Solitary metastasis from an occult renal cell carcinoma presenting as a primary lacrimal gland tumour. Orbit 5: 21-24, 1986.

22. Bernstein-Lipschitz L, Lahav M, Chen V, Gutman I, Gal R and Lipschitz M: Metastatic thyroid carcinoma masquerading as lacrimal gland tumor. Graefes Arch Clin Exp Ophthalmol 228 : 112-115, 1990.

23. Ni C, Cheng SC, Dryja TP and Cheng TY: Lacrimal gland tumors: A clinicopathological analysis of 160 cases. Int Ophthalmol Clin 22: 99-120, 1982.

24. Lee DA, Campbell RJ, Waller RR and Ilstrup DM: A clinicopathologic study of primary adenoid cystic carcinoma of the lacrimal gland. Ophthalmology 92: 128-134, 1985.

25. Lewis JE, McKinney BC, Weiland LH, Ferreiro JA and Olsen KD: Salivary duct carcinoma. Clinicopathologic and immunohistochemical review of 26 cases. Cancer 77: 223-230, 1996

26. Chia SY, Thike AA, Cheok PY and Tan PH: Utility of mammaglobin and gross cystic disease fluid protein-15 (GCDFP-15) in confirming a breast origin for recurrent tumors. Breast 19: $355-359,2010$.

27. Bhargava R and Dabbs DJ: Use of immunohistochemistry in diagnosis of breast epithelial lesions. Adv Anat Pathol 14: 93-107, 2007.

28. Kivelä T: Antigenic profile of the human lacrimal gland. J Histochem Cytochem 40: 629-642, 1992.

29. Lussier C, Klijanienko J and Vielh P: Fine-needle aspiration of metastatic nonlymphomatous tumors to the major salivary glands: A clinicopathologic study of 40 cases cytologically diagnosed and histologically correlated. Cancer 90: 350-356, 2000

30. Seifert G, Hennings $\mathrm{K}$ and Caselitz J: Metastatic tumors to the parotid and submandibular glands - analysis and differential diagnosis of 108 cases. Pathol Res Pract 181: 684-692, 1986.

31. Eveson JW, Auclair P, Gnepp DR and El-Naggar AK: Tumours of the salivary glands: Introduction. In: World Health Organization Classification of Tumours: Pathology and Genetics, Head and Neck Tumours. Barnes L, Eveson JW, Reichart P and Sidransky D (eds). IARC Press, Lyon, pp212-215, 2005.

32. Minn AJ, Gupta GP, Siegel PM, Bos PD, Shu W, Giri DD, Viale A, Olshen AB, Gerald WL and Massagué J: Genes that mediate breast cancer metastasis to lung. Nature 436: $518-524,2005$.

33. Bernard-Marty C, Cardoso F and Piccart MJ: Facts and controversies in systemic treatment of metastatic breast cancer. Oncologist 9: 617-632, 2004.

34. Roché H and Vahdat LT: Treatment of metastatic breast cancer: Second line and beyond. Ann Oncol 22: 1000-1010, 2011. 